\section{In defence of appraisal}

\author{
John Launer
}

Every registered doctor in the United Kingdom has to have an annual appraisal. This involves completing an extensive online form with reflections on the activity of the previous year, including details of continuing professional development (CPD), quality improvement projects, significant events, feedback from colleagues and patients, and any complaints and compliments received. ${ }^{1}$ The most important part of the exercise takes place a couple of weeks after this, in a one-to-one meeting with a colleague to review the completed form, generally in the context of a more wide-ranging discussion that covers the job, welfare and aspirations of the doctor concerned. This system was first introduced by the General Medical Council (GMC) in 2002, and then strengthened as one of the consequences of a judicial inquiry into the murders committed by the general practitioner, Dr Harold Shipman. ${ }^{2}$ Since 2012, British doctors have also had to undergo regular revalidation in order to continue in practice, and one of the requirements of this is to have satisfactory appraisals in each of the 5 years leading up to it. A modified version of this arrangement has recently been introduced for nurses in the United Kingdom as well. ${ }^{3}$

A few other countries have introduced elements of appraisal and revalidation similar to the British approach, especially the emphasis on CPD, ${ }^{4}$ but nowhere else has adopted an entire system on this scale. The individual reactions of doctors abroad to the idea of such a system presumably range from admiring its thoroughness and the potential protection it offers to patients, to being aghast at the time, costs, bureaucracy and level of state control involved. Within the United Kingdom itself, appraisal remains the focus of strong negative emotions among some doctors. One persistent critic has been the popular medical columnist Margaret $\mathrm{McCa}$ rtney. A piece she wrote entitled 'The false god of appraisal ${ }^{5}$ attracted a large number of vividly-expressed responses from colleagues in support. In the article, she questioned why medical colleges had signed up for 'this time wasting, navelgazing and expensive process' without questioning whether the endeavour was

Correspondence to Dr John Launer, Postgraduate Medical Journal, London WC1B 5DN, UK; johnlauner@aol.com evidence-based. McCartney has a national reputation as a champion of evidencebased practice, but the piece was uncharacteristically anecdotal. She referred merely to 'several doctors' she knew who had had 'vile slurs written on feedback documents,' but she did not cite any of the extensive research into appraisal and its effects. While showing up some negative aspects of appraisal, especially the risk of it becoming a tick-box exercise, ${ }^{6}$ the literature actually demonstrates that doctors by and large find it beneficial in terms of enhancing their learning, improving their practice or encouraging their professional development. $^{7-10}$

\section{OBJECTIVE DATA}

Misconceptions about appraisal abound, and some appeared in the responses to McCartney's piece. Appraisal is not designed to 'detect the next Shipman.' This was never its original purpose, and it patently could not do so. (Shipman himself seems to have been a very competent and conscientious physician, and anyone as wicked as him would also no doubt be clever enough to submit an exemplary appraisal.) Views formed by appraisers can never in themselves lead to any disciplinary action, let alone a refusal of revalidation. Appraisers cannot actually 'fail' anyone. Sometimes they ask doctors to provide more information to help form a fuller impression of what their practice is like. On rare occasions, appraisers may have concerns that they feel they should pass on to the local regulator. Such concerns are then triangulated with a great deal of other information, including any objective data that already exists on a doctor's performance. No action is ever taken solely on the basis of an appraiser's view. Appraisees give anonymous feedback on their appraisers, can record an objection to anything an appraiser has written in a summary of the discussion, or request a change of appraiser.

Another common criticism of appraisal is that the 'formative' or developmental support that it aims to offer is incompatible with the 'summative' or performance-related judgement that underlies revalidation. In fact, a moment's reflection makes it obvious that there is almost no activity in medical or educational practice - including consultations with patients - where doctors do not need to move flexibly between the two approaches, encouraging people to fulfil their potential whenever possible, but having to articulate concerns when needed. The obvious analogy is in the way we might promote a patient's well-being for many years, but then have to make an adverse report if they become unable to drive safely or to look after children. In reality, conversations about development and performance cannot be neatly separated.

In measured debates about appraisal, the crucial aspect usually identified is that it is a complex, multi-faceted intervention undertaken by appraisers and appraisees with a very wide range of motivations, training and skills, and in a variety of health service contexts. These contexts range from highly sophisticated ones where reflection and self-regulation are the norm, to ones that are dysfunctional. It is hardly surprising that doctors' experiences of appraisal are diverse, and their consequent views about the subject equally so. In this context, it makes little sense to claim that it is either wholly a 'false god' or an unalloyed good. Assuming appraisal is here to stay, it is more worthwhile to examine the elements most likely to enhance its value to doctors as opposed to reducing it to an empty ritual.

\section{BEHAVIOUR CHANGE AND SELF- AFFIRMATION}

In this respect the most useful guidance probably comes from a paired set of papers by Nicola Brennan from Plymouth University and her team, who offer a 'realist' review of how appraisal can achieve its desired effects. ${ }^{11} 12$ Realist reviews take the approach of analysing an existing intervention and examining what works, for whom, in what circumstances and in what respects. Brennan's team analysed 125 relevant articles on the subject in order to establish which particular circumstances led to which kinds of outcomes. Elements that they found can produce behaviour change in an appraisee included a positive attitude towards appraisal, a highly skilled appraiser, and a working environment supportive of appraisal. A skilled appraiser can also identify when the appraisee is strong in a particular area and then provide positive feedback, leading to reflection, insight and self-affirmation. A trusting relationship between the participants also makes a difference. When these contexts are absent - with an unskilled appraiser, an unsupportive environment, and an appraisee with a negative attitude towards the whole process - the outcome is likely to be 'denial', in the 
form of game-playing and perfunctory box-ticking.

This review, probably the most systematic to date, certainly confirms my own impressions as an appraiser and educator. Good training and selection of appraisers, together with resources to help doctors and organisations use the process fruitfully, are essential. Training appraisees in the skills for reflective writing can be particularly helpful in making appraisal less daunting and more productive. ${ }^{13}$ Personally, I have had an overwhelmingly positive experience of appraisal on both sides of the conversation. At its best, it can be akin to good mentorship or coaching in terms of the personal and professional development it can stimulate, particularly in relation to career decisions. ${ }^{14}$ Another impact I have seen over the years, although it is not covered in the literature, is that appraisal has encouraged dialogue and an exchange of information among colleagues in a way that was previously very uncommon. Twenty years ago, it was possible to work as a general practitioner within a few hundred metres of another practice that one had never entered, knew absolutely nothing about, and had never learnt anything from. The same was true of hospital doctors working on adjacent corridors or floors. With local colleagues now regularly appraising each other, you can no longer be a lone wolf, either in respect of your strengths, or of your weaknesses. I believe the professional discussions and connexions that have resulted from appraisal have played a part in bringing about significant culture change in the profession.

Funding The authors have not declared a specific grant for this research from any funding agency in the public, commercial or not-for-profit sectors.

Competing interests I have carried out appraisals of general practitioners for NHS England and its predecessors since 2004 and receive income for this. I taught appraisal skills at the former London Deanery, now Health EducationEngland, as part of employment there.

Patient consent for publication Not required.

Provenance and peer review Not commissioned; externally peer reviewed.

(c) Author(s) (or their employer(s)) 2019. No commercial re-use. See rights and permissions. Published by BMJ.

\section{Check for updates}

To cite Launer J. Postgrad Med J 2019;95:235-236.

Published Online First 20 May 2019

Postgrad Med J 2019;95:235-236.

doi:10.1136/postgradmedj-2019-136500

\section{REFERENCES}

1 NHS Revalidation Support Team. 2013 medical appraisal guide: a guide to medical appraisal for revalidation in England, version 4. https://www. england.nhs.uk/revalidation/wp-content/uploads/ sites/10/2014/02/rst-medical-app-guide-2013.pdf [Accessed 9 Feb 2019].

2 Her Majesty's Stationery Office. Learning from tragedy, keeping patients safe. Overview of the government's action programme in response to the recommendations of the Shipman inquiry, 2007. Available: https://assets.publishing.service.gov.uk/ government/uploads/system/uploads/attachment data/file/228886/7014.pdf [Accessed 9 Feb 2019].
3 Nursing and Midwifery Council. Revalidation: how to revalidate with the NMC, 2019. Available: https:// www.nmc.org.uk/globalassets/sitedocuments/ revalidation/how-to-revalidate-booklet.pdf [Accessed 9 Feb 2019].

4 Archer J, Pitt R, Nunn S, et al. The evidence and options for revalidation in the Australian context: final report. Plymouth: Plymouth University Peninsula School of Medicine and Dentistry, 2015.

$5 \mathrm{McC}$ artney M. The false god of appraisal. BMJ 2015;351.

6 McGivern G, Ferlie E. Playing tick-box games: Interrelating defences in professional appraisal. Human Relations 2007;60:1361-85.

7 Overeem K, Faber MJ, Arah OA, et al. Doctor performance assessment in daily practice: does it help doctors or not? A systematic review. Med Educ 2007;41:1039-49.

8 Finlay K, McLaren S. Does appraisal enhance learning, improve practice and encourage continuing professional development? A survey of general practitioners' experiences of appraisal. Qual Prim Care 2009;17:387-95.

9 Mugweni K, Kibble S, Conlon M. Benefits of appraisal as perceived by general practitioners. Educ Prim Care 2011:22:393-8

10 Zolle O, Rickenbach M, Gorrod E. The formative impact of general practice appraisals: a postAppraisal questionnaire survey. Educ Primary Care 2009:20:445-54

11 Brennan N, Bryce M, Pearson M, et al. Understanding how appraisal of doctors produces its effects: a realist review protocol. BMJ Open 2014;4:e005466.

12 Brennan N, Bryce M, Pearson M, et al. Towards an understanding of how appraisal of doctors produces its effects: a realist review. Med Educ 2017:51:1002-13.

13 Miller L. Reflective practice for appraisal and revalidation in general practice: towards new learning and improved patient safety? Educ Primary Care 2014:25:119-21.

14 Launer J. Supervision, mentoring and coaching. In: Swanwick T, Forrest K, O'Brien B, eds. Understanding medical education: evidence, theory, and practice. 3rd edn. Edinburgh: John Wiley, 2019: 179-90. 